\title{
$\operatorname{arCOS} D E S I G N$
}

\section{Design Emocional: empatia e contextualização}

Adriana Barbosa Ribeiro (PUC-Rio, Brasil)

drimeister@gmail.com

Rua Marquês de São Vicente, 225, Gávea

Rio de Janeiro, RJ, CEP: 225451-900

Vera Lucia dos Santos Nojima (PUC-Rio, Brasil)

veluc.nojima@gmail.com 


\section{Design Emocional: empatia e contextualização}

Resumo: $\mathrm{O}$ artigo aqui apresentado relaciona os resultados ainda parciais obtidos pela pesquisa de conteúdo imagético presente nos filmes de Leni Riefenstahl ao andamento das correntes do pensamento em design que se ocupam do que podemos classificar como um design emocional ou de cunho empático. A estas perspectivas teóricas contrapomos o trabalho de filósofos e neurocientistas que, por sua vez, desenvolvem pesquisas sobre empatia e moralidade no âmbito da ética.

Palavras-chave: empatia; semiótica; design emocional.

\section{Emotional Design: empathy and contextualization}

Abstract: The article here presented relates the partial results obtained by the research of imagery content appearing in the films of Leni Riefenstahl to the progress of currents of thought in Design that deal with what one can classify as an emotional or design of empathetic imprint. To these theoretical perspectives we interpose the work of philosophers and neuroscientists who, in turn, develop researches on empathy and morality in the context of ethics.

Keywords: empathy; semiotics; emotional design. 


\section{Introdução}

De acordo com as percepções coletadas ao longo do percurso de análise dos filmes de Leni Riefenstahl, especialmente o filme Triunfo da Vontade, estabelecemos, aqui, as confluências existentes no tocante ao campo do Design. Neste artigo, intencionamos discutir os pontos em que averiguamos quais as contribuições resultantes para o enriquecimento do campo teórico e metodológico do Design, especialmente aqueles que se ocupam de um Design emocional.

Os resultados da pesquisa, ainda parciais neste momento, já apontam para uma evolução das correntes que abordam o caráter emocional da prática projetual no campo. Dentre estas, podemos destacar movimentos importantes, que vêm somando esforços no sentido de uma conexão de ordem identitária entre objetos e usuários. Tal tendência pode ser exemplificada pelos esforços empreendidos por Pieter Desmet, Paul Hekkert e pesquisadores da Universidade de Delf no desenvolvimento de instrumentos utilizados na medição das emoções acarretadas por um produto em seu usuário, o Product Emotion Measurement - PrEmo.

Claramente, pessoas diferentes respondem de maneira diferente a um determinado produto. Experiência não é uma propriedade do produto, mas o resultado da interação humano-produto e, portanto, depende de quais características temporais e disposicionais o usuário traz para a interação. (DESMET е HEKKERT, 2007, p.65)

Outro autor importante ao mencionarmos o aspecto emocional do Design é Donald Norman, cujo livro The Design of Everyday Things sintetiza o aspecto emocional do design em três níveis interagindo de maneira complexa. De acordo com Norman, os três níveis da experiência emocional poderiam ser mapeados determinando as características do produto do seguinte modo:

$$
\begin{array}{ll}
\text { Design visceral } & >\text { aparência } \\
\text { Design comportamental } & >\text { o prazer e a eficácia do uso } \\
\text { Design reflexivo } & >\text { autoimagem, satisfação pessoal, memórias }
\end{array}
$$

Apesar de os exemplos dispostos por Norman se encontrarem datados e se referirem a tecnologias superadas (fonógrafo, máquina de escrever, projetor de slides, etc.), os princípios fundamentais de sua pesquisa, que pregam que produtos devem ser mais "mais agradáveis, compreensíveis e rentáveis", permanecem inalterados. Em seu trabalho, Donald Norman dispensa especial 
atenção às imagens, expondo a condição excepcional do objeto fotografia no imaginário emotivo e contextual do usuário.

FOTOGRAFIAS, mais do que quase qualquer outra coisa, tem um especial apelo emocional: elas são pessoais, contam histórias. O poder da fotografia pessoal reside em sua capacidade de transportar o observador de volta no tempo para algum evento socialmente relevantes - fotografias pessoais são lembranças, anotações e instrumentos sociais, permitindo que as memórias sejam compartilhadas através do tempo, lugar e pessoas. (NORMAN, 1998 p.50)

Tanto para o campo teórico do Design quanto para sua prática projetual, o entendimento, e mesmo a manipulação, das possíveis respostas empáticas constituem elementos chave na elaboração de sua produção.

A distinção entre os termos necessidade e desejo é uma forma tradicional de descrever a diferença entre o que é realmente necessário para as atividades de uma pessoa (necessidades) versus o que uma pessoa pede (quer). Necessidades são determinadas pela tarefa: um balde é necessário para transportar a água; algum tipo de pasta de transporte é necessária para o transporte de documentos na ida e volta ao trabalho. Desejos são determinados pela cultura, pela publicidade, pela maneira que se vê a si mesmo e sua autoimagem. Embora uma mochila ou mesmo um saco de papel funcione perfeitamente bem para o transporte de documentos, pode ser constrangedor carregar um em uma "poderosa" reunião de negócios séria. Vergonha é, naturalmente, uma emoção que reflete o senso de adequação de comportamento e é realmente situada na mente. Designers de produto e executivos de marketing sabem que o desejo muitas vezes pode ser mais poderoso do que as necessidades para determinar o sucesso de um produto. (NORMAN, 2004, p. 43)

No Brasil, o Design Emocional elaborado por Vera Damásio e o Design Atitudinal desenvolvido pela professora Lucy Niemeyer, este com base na semiótica de Peirce, representam exemplos de métodos que visam tanto avaliar quanto propor o apelo emocional promovendo contornos e respostas empáticas por parte do usuário. 
O ferramental de análise centrado na semiótica peirceana proporciona a identificação dos pontos nevrálgicos da relação entre imagens e sua possível decodificação. Esta possível transcrição é matéria prima para o projeto de Design. Sabemos ser possível dotar objetos de determinadas características que exercem este apelo emocional sobre o destinatário. Entretanto, as questões chave que abrem possibilidades de contribuição e representam avanço para o campo do Design se desdobram em questionamentos sobre a evolução empática de um Design de cunho emocional.

Em primeiro lugar: poderíamos definir este apelo emocional incutido pelo Design em seus projetos como um apelo empático? Ou seja, seria "empatia" o nome desta emoção vicária, ou identitária, componente dos projetos de Design, que visam a produção de objetos como Donald Norman desejaria "mais agradáveis, compreensíveis e rentáveis"?

Em segundo lugar: Considerando-se que a manipulação do apelo empático seja corrente no campo do Design, assim como no campo das Comunicações e da Publicidade mais admitidamente, nos questionamos sobre o aspecto ético da prática.

Em seu trabalho A Empatia é Necessária para a Moralidade?, Prinz rejeita a definição de empatia "como uma resposta emocional orientada ao outro e congruente com a percepção de bem-estar de outra pessoa", proposta por Batson, dissecando-a em duas partes distintas. Prinz afirma que o foco na preocupação e no bem-estar demonstra uma falha em distinguir entre "descobrir-se com sentimentos por um objeto" e "descobrir-se com sentimentos em-nome-de um objeto". Prinz também aponta a fraqueza da definição de Darwall (1998, pág. 261) que diz que "Empatia consiste em sentir o que alguém imagina que outro sente, ou talvez deva sentir (medo, digamos), ou em alguma cópia imaginada destes sentimentos, se este alguém vier assim a se preocupar... ou não", rejeitando dois aspectos desta definição: primeiro, o apelo à imaginação, por ser este muito intelectual; segundo, resiste à aplicação de Darwall de "empatia" em casos onde se tem a sensação de que alguém deva sentir, mas não sente. Nesta pesquisa nos alinhamos com a definição de Batson, apenas com a ressalva de que, concordando com Prinz, em nosso entendimento, a empatia não pressupõe necessariamente uma preocupação ou mesmo uma preocupação com o bem-estar do outro, mas antes, pressupõe uma emoção de ordem identitária sendo dirigida para fora, projetada em outrem.

... quando uma pessoa diz que um curso de ação é obrigatório, esse julgamento expressa o que poderia ser chamado de um sentimento prescritivo. Um sentimento prescritivo é uma disposição emocional complexa. Se alguém tem este sentimento 
sobre uma forma particular de conduta, então está disposto a exercer essa conduta, e este alguém está disposto a se sentir mal se não. Este alguém também está disposto a condenar aqueles que não praticam essa forma de conduta. (PRINZ, 2007, p.4)

Paul Slovic introduz a questão da exterioridade relacionada à empatia. Entretanto, embora rapidamente, Prinz alerta para o fato de que nossa capacidade de experimentar emoções vicárias está de alguma maneira relacionado com a proximidade social e proeminência. Este ponto parece ser de extrema importância quando pensamos no conceito de völkish nacionalista, pregnante nos filmes de Riefenstahl. Este conceito de völkish ou völkische Bewegung (movimento völkish) está centrado nas qualidades nativas do homem germânico, na valorização das tradições, na fertilidade da terra, na supremacia da raça ariana, sendo um dos pilares da própria formação dos ideais nazistas. O conceito é fundamental também na elaboração de uma unidade discursiva a respeito da ideologia nazista e dá unidade étnica aos alemães, podendo mesmo ser entendido como constituinte do racismo e antissemitismo nazista. Desta maneira, embora sem aprofundar a questão, Prinz parece estar correto quando afirma que "Se você é alguém de fora ou está locado em uma terra distante, meu grau de empatia pode ser reduzido correspondentemente".

Em seu livro, o historiador Daniel Goldhagen afirma que os autores dos assassinatos em massa durante o nazismo eram cidadãos alemães comuns, provenientes de todas as classes sociais, e que formavam uma amostra bastante representativa do adulto alemão; que não eram em número pequeno, mas um mínimo de cem mil alemães e provavelmente muitos mais foram assassinos; e que esses cidadãos alemães comuns eram, em geral, "dispostos, e mesmo ansiosos carrascos do povo judeu, inclusive de crianças judias" (GOLDHAGEN, 1999). Ele também demonstra que o antissemitismo eliminacionista que movia esses alemães foi extremamente difundido na sociedade alemã durante, e até mesmo antes do período nazista. Este modelo antissemita, basicamente, pregava que judeus eram diferentes dos alemães, que essas supostas diferenças residiam em sua biologia, sendo, portanto, imutáveis. Esta observação coaduna com a observação de Prinz sobre o declínio da empatia quando se é "alguém de fora", isto parece se dever ao fato de que há um enfraquecimento do componente identitário da empatia.

Apesar das assertivas de Prinz sobre a possibilidade, ou mesmo a desejabilidade de reconhecermos respostas empáticas na face de nossos interlocutores, podemos verificar no projeto de Hitler que este lança mão deste artifício estratégico, com uma consciência bastante efetiva das características 
empáticas das quais um orador deve dispor. Apesar de não ser de fato uma pré-condição epistêmica para a moralidade, conforme Prinz adverte, este parece ser um meio eficaz de sensibilizar interlocutores. De maneira amoral, diversos líderes ao longo da história se utilizaram, e continuam a se utilizar, deste subterfúgio.

Suponha que eu aprenda que minhas palavras machucaram você por meio de seu testemunho, mas eu não sinto uma resposta empática. Isto talvez não seria razão suficiente para que eu me comprometa com uma censura própria adequada? Assumir o contrário é entrar em uma teoria controversa de atribuição de estado mental. É equivalente a sugerir que podemos entender a mente dos outros apenas simulando esta. Mas não há razão para pensar que isto é verdade. (...) Isto sugere que nós geralmente percebemos emoções quando as experimentamos vicariamente. Mas isso seria uma interpretação exagerada da evidência que sugere que precisamos simular a fim de que possamos atribuir emoções. (PRINZ, 2005)

De fato, Hitler parecia dispor de uma consciência estratégica bastante elevada das qualidades empáticas da oratória e chega mesmo, de maneira literal, a distinguir entre as capacidades de convencimento da palavra escrita e do discurso presencial, pondo bastante ênfase na figura do orador.

Na fisionomia dos ouvintes poderá ele (o orador) observar, primeiro, se está sendo compreendido, segundo, se todos os ouvintes podem acompanhá-lo, terceiro, se estão persuadidos da justeza do que lhes apresenta. Na hipótese de verificar que não está sendo compreendido, procederá a uma explicação tão clara, tão simples, que todos a aceitarão. Se sentir que o auditório não pode acompanhá-lo em todos os seus raciocínios, ele, então, exporá suas ideias lenta e cuidadosamente, até que os espíritos intelectualmente mais fracos possam apanhá-las. Se compreender que os ouvintes não estão convencidos da correção de seus argumentos, repeti-los-á tantas vezes quantas forem necessárias, aduzindo sempre novos argumentos e fazendo ele mesmo as objeções que julga estarem no espírito do auditório. Continuará assim até que o último grupo de oposição demonstre, pela sua maneira de portar-se e por sua fisionomia, que capitulou ante os raciocínios apresentados. (HITLER, 1929:435) 
Conforme o trabalho de Slovic aponta, a "arte é o antídoto que pode nos chamar de volta do limite do entorpecimento, restaurando nossa capacidade de sentir pelo outro". (KINGSOLVER apud SLOVIC, págs. 231-232). O cinema dentre as diversas formas de manifestação artística parece ter um especial papel na difusão deste "antídoto contra o entorpecimento", porém, durante a era nazista parece ter operado exatamente da maneira oposta. Este discurso do líder empático foi amplificado e ajudou a derrubar a rejeição a que Hitler denominou "obstrução oriunda do sentimento".

Não raramente surge o caso da existência de poderosos preconceitos, que não vêm da razão, mas ao contrário, são na maior parte, inconscientes e com base apenas nos sentimentos. É mil vezes mais difícil transpor essa barreira de repulsa instintiva, de ódio ou de preconceitos negativos, do que corrigir uma noção errada ou incorreta. A ignorância, falsas concepções podem ser removidas por argumentos, a obstrução oriunda do sentimento, nunca. Só um apelo a essas forças ocultas pode ser bem sucedido nesse caso. Isso é quase impossível para um escritor. Só um orador pode ter esperanças de consegui-lo. (HITLER, 1929, p.435)
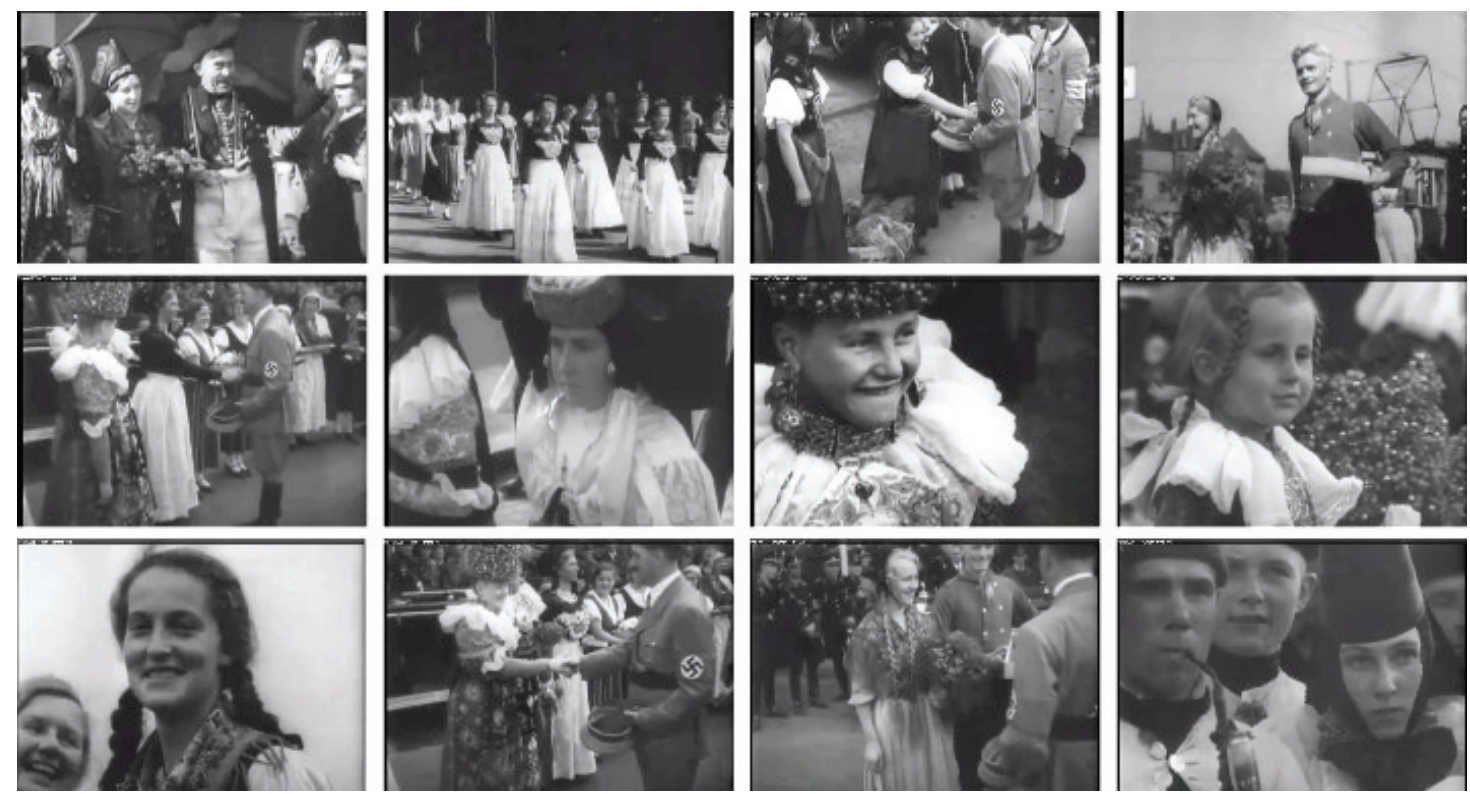

Figura 1. Sequência do filme Triunfo da Vontade. 
O ideal de eugenia perpassa o filme de Riefenstahl, Triunfo da Vontade, como um todo e este ideal de supremacia ariana bem poderia ser tomado como seu tema de base. Outras sequências são igualmente expressivas desse potencial sígnico, tal como a sequência em que jovens viris, musculosos, saudáveis e louros, tomam café da manhã se preparando para o congresso, se divertem em lutas e jogos entre seus camaradas no acampamento da juventude hitlerista. Contudo, nenhuma outra é mais literal com relação ao conceito de völkish (étnico) do que a sequência dos camponeses em seus trajes "folclóricos".

Estas tomadas de fazendeiros e camponeses vestidos em trajes típicos, trazendo ofertas de sua colheita, têm um forte apelo ao völkish nacionalista alemão. Estas cenas despertam a curiosidade também pelo caráter exótico da indumentária camponesa. Essa estranheza inicial (em que predomina um acento remático do interpretante para nossa observação) ${ }^{1}$, demonstra um forte contraste tanto com a população exaltada que recepciona Hitler quanto com a massa uniformizada presente em todos os outros momentos do filme.

Ainda assim, a análise cinematográfica à luz da semiótica peirceana mostrou-se fundamental para a identificação do espírito da época, e sobretudo para este discurso basilar fosse identificado. Conforme aponta o semioticista Johannes Ehrat com especial clareza, rara mesmo entre as teorias analíticas do cinema, filmes são signos complexos e, simultaneamente, representação antes mesmo que seu enredo seja conhecido.

A especificidade cinematográfica, ou a verdadeira natureza sígnica do cinema, é vista quando examinamos o princípio da semiose. Como um evento relacional, um signo traz essencialmente três diferentes correlatos para a relação. Isto pode ser construtivo ou degenerativo, como já vimos. O Significado ou cresce em generalidade e diminui em imprecisão, ou torna-se cada vez mais vago e menos geral. Se significado é inteiramente geral, seu terceiro correlato determina completamente o signo. Uma relação não é genuína (isto é, degenerativa) se engloba características ou primeiridades superiores à determinação completa do terceiro desta relação. Este "salientar", ou excesso de qualidade de algum caráter, é típico do cinema. (EHRAT, 2005, p. 138)

1. REMA - O Interpretante pode ser abordado em três níveis. Em um nível primeiro, há uma imprecisão de sentido, uma sensação, uma indeterminação, que se dá no instante inicial de contato com o novo - um certo espanto, uma surpresa, uma indefinição. O que é? O que é para mim? Este âmbito de conotações, amplo e impreciso, é o que se chama Rema (ver NIEMEYER, ROSENTHAL e RANSDELL). 
A interpretação de sentido nos filmes de Leni Riefenstahl nos é facultada por uma análise que inclui o momento político vivido pela Alemanha, e nos dá a pensar sobre o que podemos reconhecer sobre estas imagens hoje, e que não estava disponível para um observador contemporâneo deste filme. É, da mesma maneira, simultaneamente como ensaio e documento, que uma investida aos filmes nos permite tal interpretação, pois conforme Comolli observa, (Comolli, 2008) "o olhar que sustenta a documentação faz parte da própria documentação", nos permitindo inferir seu sentido. Em outras palavras, é possível reconhecer, nos dias atuais, a esperança confirmada daquele povo depositada na figura de Hitler, que fortificava a economia da Alemanha após anos de restrições. As ambições megalomaníacas de Hitler, a Noite dos Vidros Quebrados, o advento da II ${ }^{\mathrm{a}}$ Guerra, o Holocausto, tudo isso somente está acessível ao olhar contemporâneo.

Encontramos, bastante retratadas, as massas fascistas e a manipulação imagética dos elementos que possivelmente despertaram esta emoção identitária de que a empatia parece dispor. Assim, conhecedores dos desdobramentos catastróficos destes eventos para a humanidade, podemos concordar com Prinz sobre os perigos da empatia para a formulação de julgamentos morais.

Conforme elucida o semioticista Ivo Assad, a semiótica, ou lógica, estaria para Peirce em uma relação de interdependência para com a ética e a estética. Ao se referir ao Pragmatismo peirceano, Assad nos mostra caminhos para que sejam desfeitos mal entendidos a respeito deste, ressaltando na obra peirceana "uma interdependência entre as ciências normativas, de tal modo que a Lógica dependa da Ética, e esta da Estética. Trata-se de um resgate contemporâneo das relações, já presentes na Filosofia antiga, entre o Verdadeiro, o Bem e o Belo". (ASSAD, 2002, p.121)

Na medida em que o significado de uma concepção é o modo como ela afeta a conduta, e esta é "ação voluntária que é autocontrolada", decorre que o pragmaticista, nas palavras do autor, "situa o significado num tempo futuro; pois a conduta futura é a única conduta capaz de ser submetida ao autocontrole". Esta ideia de autocontrole medeia a aproximação entre Lógica e Ética na Filosofia de Peirce. De qualquer modo, é de se antever que o caráter lógico que o autor atribui à máxima, fazendo-a estar implicada nas três formas de argumento, que denomina abdução, dedução e indução, tangencia, senão profundamente se imbrica, com uma filosofia da conduta, cujo caráter, por sua vez, encontra-se no âmbito de uma Ética. (ASSAD, 2002, p.120) 


\section{Dois casos de Design Emocional na Alemanha nazista}

A leitura dos filmes de Riefenstahl possibilitou a identificação destas emoções identitárias refletidas em seus filmes. Observamos que os ideais nazistas permeavam aquela sociedade. Ainda assim, sabedores de todas as maneiras condenáveis das práticas nazistas, encontramos projetos que seriam extremamente populares nos dias atuais. Como exemplo, podemos citar as campanhas antitabagistas, projeto pessoal e caro a Hitler.

O fracasso em reduzir as taxas de tabagismo na Alemanha, da maneira que são reduzidas em vários outros países, é atribuída à relativa falta de iniciativas de saúde pública destinadas a impedir o hábito de fumar. Uma das razões para a falta de tais iniciativas pode ser a associação das campanhas antitabagistas nos locais de trabalho, no transporte público e nas escolas com as campanhas antitabagistas sob o regime nazista, e que estas tenham permanecido por um longo período na memória popular. (SMITH, STRÖBELE E EGGER, 1994 p. 222)

A Alemanha nazista esteve décadas à frente de outros países na promoção de reformas na área da saúde que hoje consideramos como progressivas e socialmente responsáveis. Além das campanhas antitabagistas, outras peças gráficas pregavam restrições relacionadas ao uso do amianto, de pesticidas e corantes alimentícios. Para o historiador Robert Proctor, a promoção do vegetarianismo, parte constitutiva da cultura völkish, exemplifica sua conclusão de que as prospectivas naturistas do nazismo surgiram a partir do ideal de uma utopia racial reservada exclusivamente à promoção dos ideais de pureza racial alemã.

No Brasil, o Programa de Controle do Tabagismo e Outros Fatores de Risco de Câncer é um programa de Estado, coordenado pelo Instituto Nacional de Câncer (INCA) do Ministério da Saúde, em articulação com outros setores do governo, constituindo-se em um programa amplo. A legislação brasileira restringe a publicidade tangendo também as políticas tributária e agrícola.

Desde o ano de 2001, um projeto coordenado pelo Instituto Nacional de Câncer, em cooperação com a Agência Nacional de Vigilância Sanitária, com o Laboratório de Neurobiologia da Universidade Federal do Rio de Janeiro, Laboratório de Neurofisiologia do Comportamento da Universidade Federal Fluminense e com o Departamento de Artes \& Design da Pontifícia Universidade Católica do Rio de Janeiro, desenvolve novas advertências sanitárias para as embalagens dos produtos derivados do tabaco. O projeto se utiliza de imagens impactantes visando criar repulsa e, assim, inibir o hábito do fumo. 
O grau de aversidade encontrado na avaliação da amostra está de acordo com estudos prévios que demonstram reatividade neurofisiológica relacionada a atitudes de afastamento. Os dados quantitativos permitiram a elaboração de um índice de aversividade dos protótipos, que serviu como um dos critérios para a seleção das novas advertências sanitárias. (INCA, 2008. p.36)

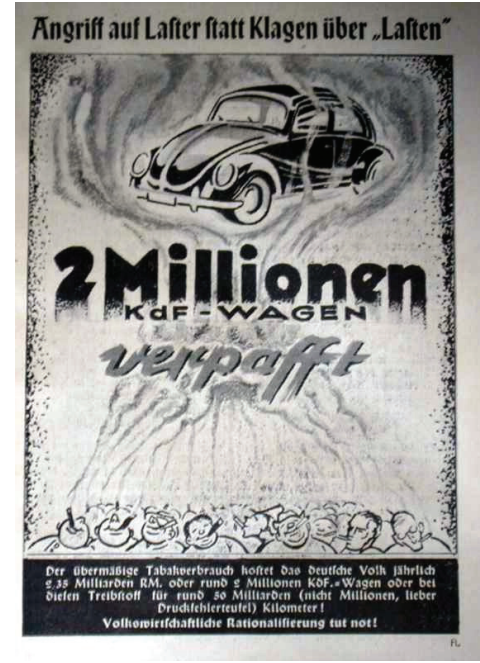

Figura 2. Campanha nazista anti-tabaco. Fonte: (PROCTOR, 1999, p.197)

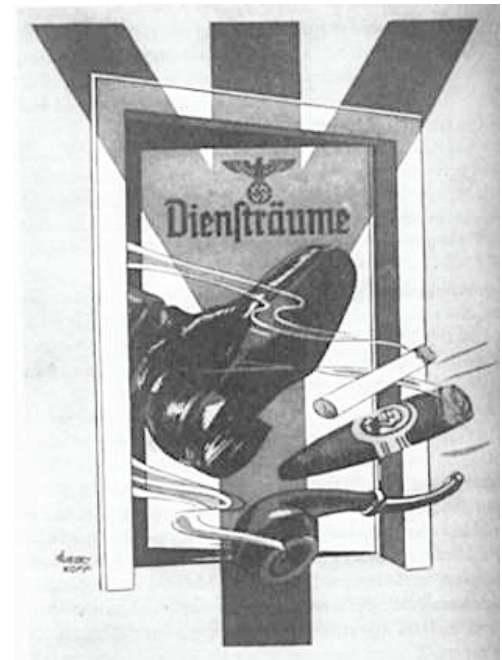

Figura 3. Campanha nazista anti-tabaco. Fonte: (PROCTOR, 1999, p.197)

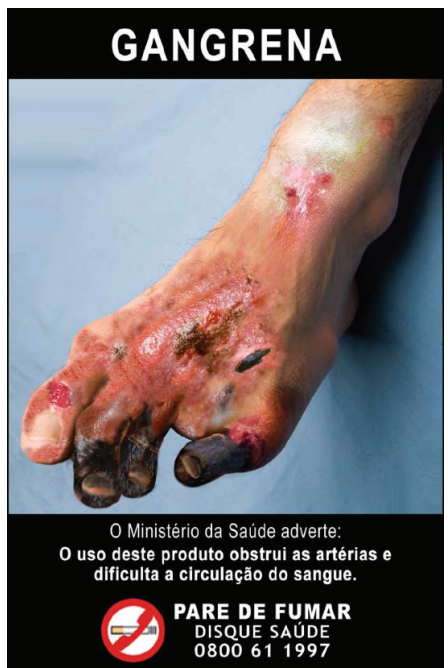

Figura 4. Imagem e advertência anti-tabaco no Brasil. Fonte: (INCA, 2009, p.46)

Outro exemplo de projeto nazista e que se popularizou através dos tempos é o design automobilístico da Volkswagen, o cativante "Fusca".

O conceito de "Volks Auto", ou "Volks Wagen", expressões que traduzem a ideia de "carro do povo" já existia desde o final da década de 1920. Enquanto a Alemanha enfrentava uma dura recessão, e tinha um dos piores índices de motorização da Europa, o projetista austríaco Ferdinand Porsche, notório nazista condenado à prisão no fim da guerra, abria seu escritório de design, o Konstruktionbüro, em Berlin, 1931. Porsche também tinha planos para o VolksAuto e construiu um protótipo de carro popular com mecânica fornecida pela Zündapp, e carrocerias Reutter, que foram batizados de "Tipo 12". 


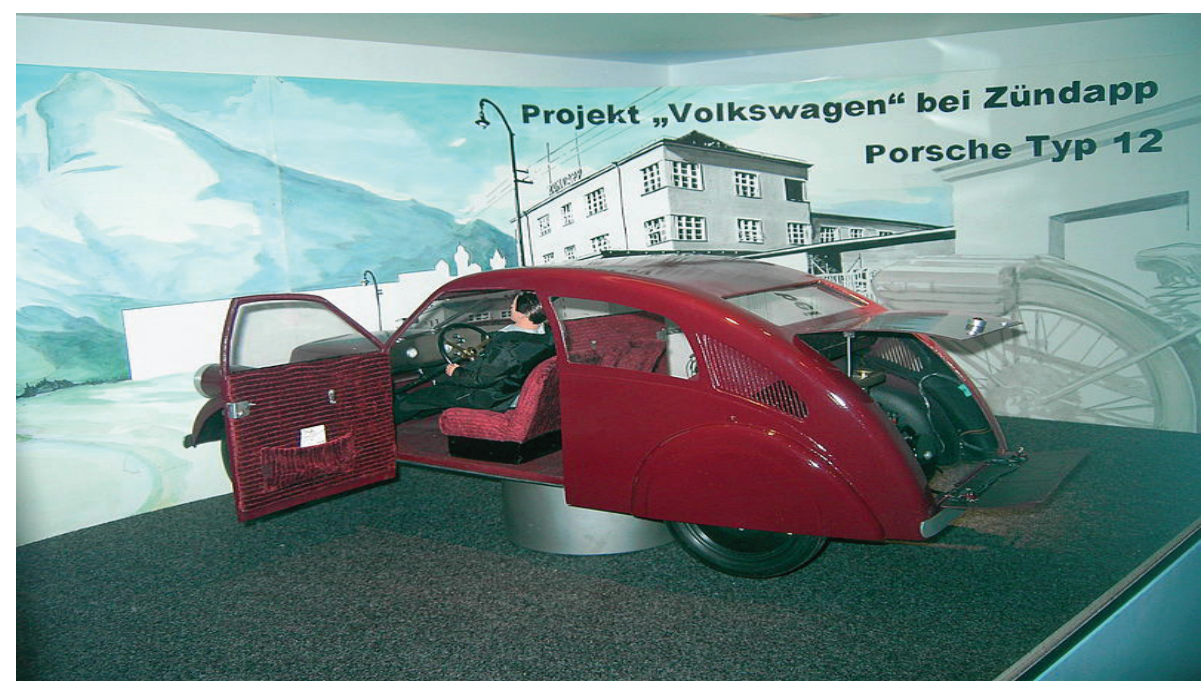

Figura 5. Porsche Typ12. Fonte: Museu da Cultura Industrial de Nuremberg

Hitler lera sobre Henry Ford na prisão e queria um "carro do povo", feito por trabalhadores alemães, auxiliando na realização da plataforma política de seu partido. Hitler estava decidido a financiar uma empresa estatal para produzir os automóveis que trafegariam por suas recém-inauguradas autobahns.

Três nomes lhe foram sugeridos para encampar o projeto: Josef Ganz, Edmund Rumpler e Ferdinand Porsche. Sendo os dois primeiros judeus e Porsche, famoso pelo seu trabalho na Daimler, que Hitler admirava.

Jacob Werlin, assessor para assuntos automotivos de Hitler, e amigo pessoal dos dois, intermediou o encontro entre Porsche e Hitler. Neste encontro, Hitler tinha pronta uma lista de exigências a serem cumpridas por Porsche: o carro deveria carregar dois adultos e três crianças e alcançar e manter a velocidade média de $100 \mathrm{~km} / \mathrm{h}$. O consumo de combustível não deveria ultrapassar os $13 \mathrm{~km} /$ litro devido à pouca disponibilidade de combustível. O motor deveria ser refrigerado a ar, dada a escassez de garagens aquecidas. O carro deveria carregar três soldados e uma metralhadora, e seu preço deveria ser menor do que 1.000 marcos (preço de uma boa motocicleta na época). 


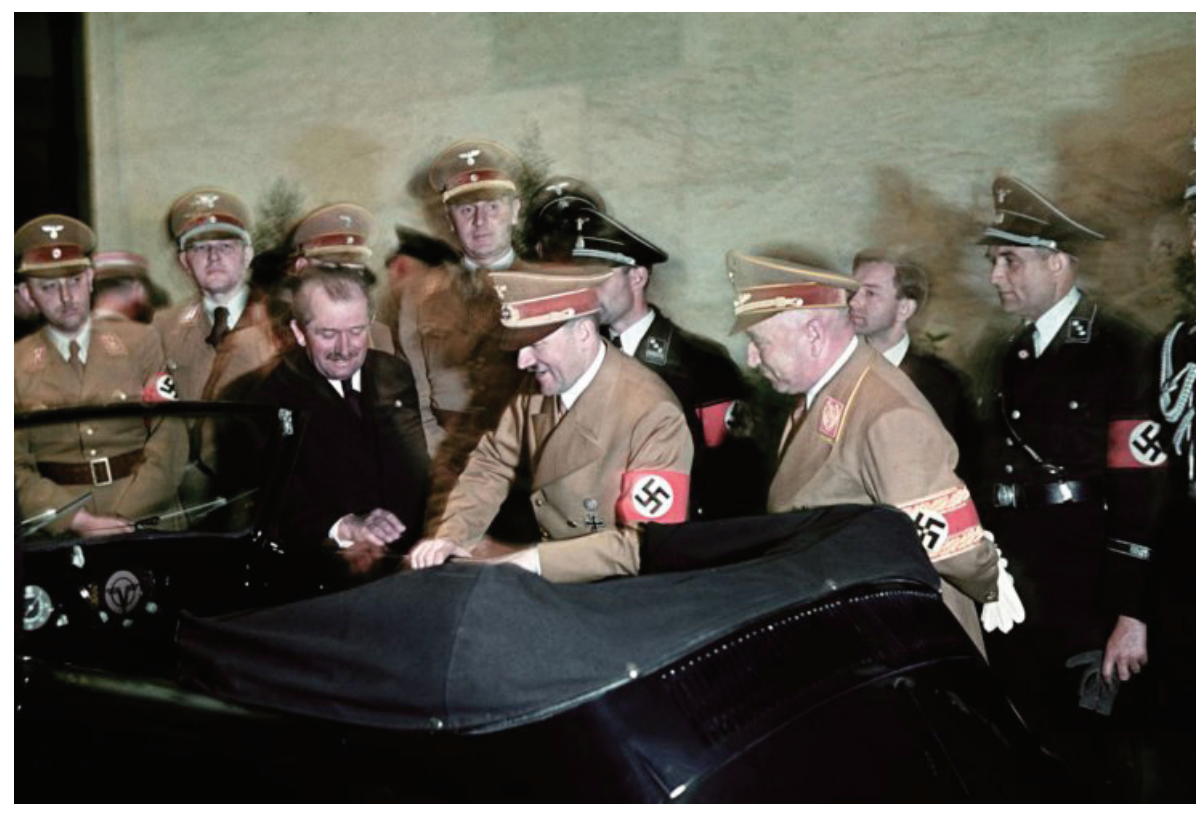

Figura 6. Porsche presenteia Hitler com um Fusca conversível pelo seu $50^{\circ}$ aniversário. Fonte: http://life.time.com/history.com

Certamente, a ideia do carro extremamente popular, de linhas arredondadas, familiar, econômico que o Fusca ocupa em nosso imaginário, no contexto da contemporaneidade brasileira, em nada reflete o ideário imagético nazista. A ideia de nazismo forma, involuntariamente, imagens duras que não coadunam com o projeto do Fusca, conforme o que entendemos em nosso interpretante dinâmico ${ }^{2}$, a que o signo Fusca atualiza.

2. A terceiridade no interpretante dinâmico indica a presença de um propósito ou intencionalidade guiando as ações do Intérprete do signo. 

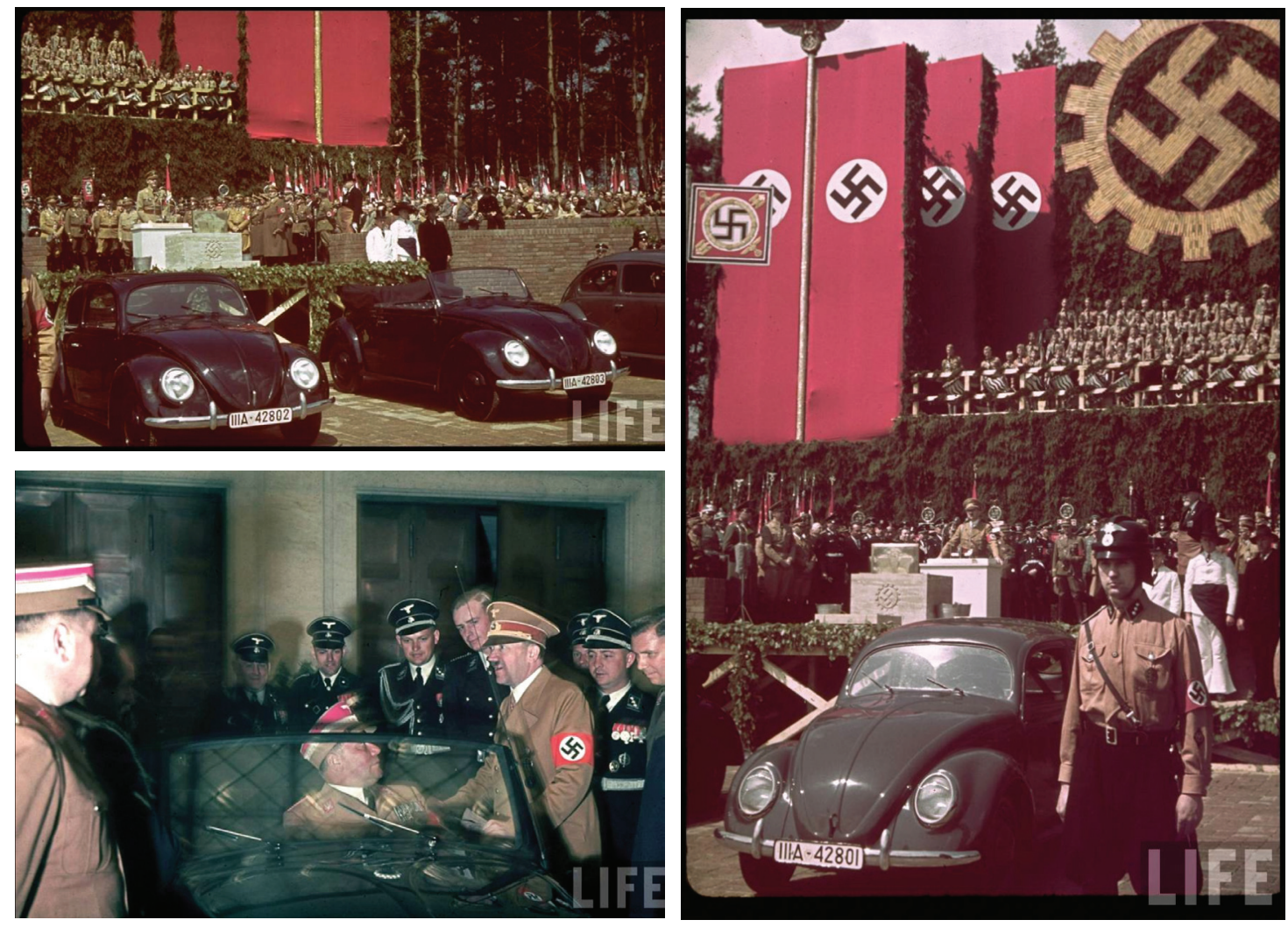

Figuras 7,8 e 9. Comemorações do $50^{\circ}$ aniversário de Hitler.

Fonte: http://life.time.com/history.com

\section{Conclusão}

A experiência frente às imagens, deixa excepcionalmente evidente o espírito da época (zeitgeist), e, em determinados casos, conforme pudemos aferir, até mais do que o espírito dos filmes analisados (filmgeist). Podemos vislumbrar uma contribuição para o avanço das pesquisas e para os métodos de verve emocional no campo do Design. Poderíamos traduzir este avanço como um novo escopo aliado a uma crescente necessidade de auto-avaliação, levando-se em consideração uma análise mais profunda do espírito de época e um estudo mais ampliado do contexto para o qual o Design projeta. Tais questionamentos morais a respeito da possibilidade ou mesmo da desejabilidade de municiar projetos com qualidades apreciativas, ou emocionais, poderiam (deveriam) fazer parte das práticas no campo. 


\section{Referência bibliográfica}

BATSON, C. D., O’Quin, K., Fultz, J., Vanderplas, M., \& Isen, A. Self-reported distress and empathy and egoistic versus altruistic motivation for helping. Journal of Personality and Social Psychology, 45, 706-718. 1983.

How social an animal? The human capacity for caring. American Psychologist, 45, 336-346. 1990.

Althruism in Humans. Oxford University Press. 2011.

BELLOUR, Raymond. Analys of Film; trad. Constance Penley. Indiana University Press. 2000. USA

COMOLLI, J-L. "Mauvaises Fréquentations: document et spectacle". In: Images Documentaires. 2008.

DESMET, P. M. A., e Hekkert, P. Framework of product experience. International Journal of Design, 1(1), p.57-66. 2007.

When a Car Makes You Smile: Development and Application of an Instrument to Measure Product Emotions, in: Advances in Consumer Research vol. 27, eds. Stephen J. Hoch and Robert J. Meyer : Association for Consumer Research, p.111-117. 2000.

EHRAT, Johannes. Cinema and Semiotic: Peirce and Film Aesthetics, Narration, and Representation. University of Toronto Press Inc. Canada, 2005

GOLDHAGEN, Daniel Jonah. Hitler's Willing Executioners: Ordinary Germans and the Holocaust. Ed. Random House Inc. Vintage Books. New York. USA. 1996

Motives, Causes, and Alibis: A Reply to My Critics. The New Republic 215, 26. 1996.

HITLER, Adolf. Minha Luta. Rio de Janeiro: Livraria do Globo. 1934 
HOFFMAN, Martin L. Empathy and moral development: The implications for caringandjustice.Cambridge,UK:CambridgeUniversityPress.2000.Disponível em:<http://catdir.loc.gov/catdir/samples/cam032/99029669.pdf> Acesso em: 2 set. 2012.

INCA. Instituto Nacional de Câncer (Brasil). Coordenação de Prevenção e Vigilância. Brasil: advertências sanitárias nos produtos de tabaco 2009. Instituto Nacional de Câncer. - Rio de Janeiro: INCA, 2008.

KINGSOLVER, B. High tide in Tucson. New York: Harper Perennial Edition. 1996.

MANN, Michael. Fascists. New York City: Cambridge University Press, 2004.

The Rise and Fall of Fascism. UCLA Center for European and Eurasian Studies, UCLA International Institute. 2004. Disponível em: <http:// www.escholarship.org/uc/item/9pg469w2 > Acesso em: 8 abr. 2011.

NIEMEYER, Lucy. Elementos de semiótica aplicados ao design. Rio de Janeiro: 2ed: Ed. 2AB, 2007.

NORMAN, Donald A. Emotional design: why we love (or hate) everyday things. Basic Books. Cambridge, MA. USA. 2004.

PAXTON, Robert O. Anatomy of Fascism. Vintage Books. New York. 2005.

.The Five Stages of Fascism. The Journal of Modern History, Vol. 70, No. 1. (Mar., 1998), pp. 1-23.

PEIRCE, Charles Sanders. Semiótica. São Paulo: ed. Perspectiva, 1977.

Collected Papers. 1931. Disponível em: <http://www.textlog.de/ peirce_principles.html> Acesso em: 10 out. 2007.

PEUKERT, Detlev, The Weimar Republic. $1^{\text {st }}$ paperback ed. Macmillan, 1993. PRINZ, Jesse. Against Emphaty. The Southern Journal of Philosophy. Special Issue: Spindel Supplement: Empathy and Ethics.Vol. 49, p. 214-233. 2011.

Is empathy necessary for morality? In Empathy: Philosophical and Psychological Perspectives. Oxford University Press. 2009. 
PROCTOR, Robert. The Nazi War on Cancer. Princeton University Press. 1999.

RIEFENSTAHL, Leni. The Sieve of Time: The Memoirs of Leni Riefenstahl. London: Quartet Books, 1992.

SANTAELlA, Lucia. A Percepção. Uma teoria semiótica. São Paulo: $2^{\text {a }}$ ed. Experimento, 1998.

Matrizes da linguagem e pensamento: sonora visual verbal: aplicações na hipermídia. 3 ed. São Paulo: ed. Iluminuras: FAPESP, 2005 a.

A teoria geral dos signos: semiose e autogeneração. São Paulo: Ática, 1995.

. Semiótica aplicada. São Paulo: Pioneira Thomson Learning, 2005c.

Comunicação e Pesquisa - Projetos para Mestrado e Doutorado. $1^{\mathrm{a}}$ ed.Ed. São Paulo; Hacker Editores;2001.

SANTAELLA, Lucia; NÖTH, Winfried. Imagem: cognição, semiótica, mídia. 4 ed. São Paulo: Iluminuras, 2005.

Comunicação e semiótica. São Paulo: Hacker Editores, 2004.

SLOVIC, Paul. If I Look at the Mass I Will Never Act: Psychic Numbing and Genocide. Judgment and Decision Making, Vol. 2, pp. 79-95, 2007. Disponível em: <http://ssrn.com/abstract=1569098> Acesso em: 15 ago. 2012.

SMITH, George Davey; STRÖBELE, Sabine A.; EGGER, Matthias. Smoking and health promotion in Nazi Germany. Journal of Epidemiology and Community Health. 1994;48:220-223 doi:10.1136/jech.48.3.220. Disponível em: <http://www.ncbi.nlm.nih.gov/pmc/articles/PMC1059950 /pdf/jepicomh00198-0004.pdf> Acesso em: 8 set. 2013. 
Recebido em: 05/06/2013

Aceito em: 01/10/2013

\section{Como citar}

RIBEIRO, Adriana Barbosa; NOJIMA, Vera Lucia dos Santos. Design emocional: empatia e contentualização. Arcos Design. Rio de Janeiro: PPD ESDI - UERJ. Volume 7 Número 2 Dezembro 2013. pp. 94-112. Disponível em: [http://www.e-publicacoes. uerj.br/index.php/arcosdesign]

\section{DOI}

10.12957/arcosdesign.2013.12184

\section{c) (i) (2)}

A Revista Arcos Design está licenciada sob uma licença Creative Commons Atribuição - Não Comercial - Compartilha Igual 3.0 Não Adaptada. 